\title{
Multiple Tolerances and Dye Decolorization Ability of a Novel Laccase Identified from Staphylococcus Haemolyticus
}

\author{
Xingxing Li' ${ }^{1}$, Dongliang Liu' ${ }^{1}$, Zhaowei $\mathrm{Wu}^{1}$, Dan Li ${ }^{1}$, Yifei Cai ', Yao Lu', Xin Zhao ${ }^{1,2}$, and Huping Xue ${ }^{1 *}$ \\ ${ }^{1}$ College of Animal Science and Technology, Northwest A\&F University, Yangling, Shaanxi 712100, P.R. China \\ ${ }^{2}$ Department of Animal Science, McGill University, Quebec, Canada

\begin{abstract}
Laccases are multicopper oxidases with important industrial value. In the study, a novel laccase gene (mco) in a Staphylococcus haemolyticus isolate is identified and heterologously expressed in Escherichia coli. Mco shares less than $40 \%$ of amino acid sequence identities with the other characterized laccases, exhibiting the maximal activity at pH 4.0 and $60^{\circ} \mathrm{C}$ with 2,2 '-azino-bis (3ethylbenzothiazoline-6-sulphonic acid) diammonium salt (ABTS) as a substrate. Additionally, the Mco is tolerant to a wide range of $\mathrm{pH}$, heavy metal ions and many organic solvents, and it has a high decolorization capability toward textile dyes in the absence of redox mediators. The characteristics of the Mco make this laccase potentially useful for industrial applications such as textile finishing. Based on BLASTN results, mco is found to be widely distributed in both the bacterial genome and bacterial plasmids. Its potential role in oxidative defense ability of staphylococci may contribute to the bacterial colonization and survival.
\end{abstract}

Keywords: Laccase, staphylococci, dye decolorization, tolerance

Received: October 28, 2019 Accepted: January 20, 2020

First published online: January 23, 2020

*Corresponding author Phone: $+86-29-87080899$ Fax: +86-29-87080899 E-mail:xuehuping@hotmail.com

Supplementary data for this paper are available on-line only at http://jmb.or.kr.

pISSN 1017-7825 elSSN 1738-8872

Copyright(C) 2020 by The Korean Society for Microbiology and Biotechnology

\section{Introduction}

Laccases (benzenediol: oxygen oxidoreductase, E.C. 1.10.3.2), a group of copper-containing polyphenol oxidases, can oxidize a variety of phenolic and phenolate compounds by degrading them into smaller components and reduce molecular oxygen to water [1]. Due to their broad substrate specificity, laccases can be used for several industrial applications, such as dye decolorization in textile industries, detoxification of recalcitrant environmental pollutants, organic synthesis as a biocatalyst and bioremediation [1,2]. The active site of laccases usually contains four copper ions [3], therefore the four copper binding regions L1, L2, L3, and L4 are considered as the standards for the identification of laccases [4].

In general, laccases are well-known enzymes widespread among fungi, especially ascomycetes, deuteromycetes and basidiomycetes. Fungal laccases usually show a higher redox potential than bacterial laccases $[5,6]$. However, laccases derived from fungal origin unfortunately not only lose some of their activities in alkaline conditions but also are sensitive to high temperature as well as high salt concentration $[7,8]$. Because of the lack of efficient heterologous expression hosts, the production of functional fungal laccases for industrial use is often difficult and needs a long time for cultivation [9]. Although site-directed mutagenesis and directed evolution are two major approaches to improving the performance of enzymes [10-12], expanding the pool to screen novel laccases is also of importance in the study. Recently, progress has been made in the investigation and isolation of prokaryotic laccases. Bacterial laccases may have potential to possess quite unique activities in physiology and biology at an extreme temperature and $\mathrm{pH}$ compared to the fungal laccases [13]. A laccase Lbh1 from Bacillus halodurans has been reported to exhibit chloride tolerance and show functional activity under the alkaline condition [14]. Another example involved the use of laccase HB27 derived from Thermus thermophiles, proving that an apparently high thermostable laccase (the highest ever reported in published literature) can be resistant at $85^{\circ} \mathrm{C}$ and incubated for $10 \mathrm{~min}$ [15]. In addition, bacterial laccases can be easily expressed in heterologous hosts like Escherichia coli, and the identification of functional prokaryotic laccases may provide a new alternative for industrial and agricultural applications.

Gram-positive bacteria staphylococci mainly reside in mucous membranes of humans and animals. A recent study found that $S$. aureus has a great ability to decolorize the azo and triphenylmethane dyes. Nevertheless, laccase gene was not identified or characterized in this case [16]. In the present study, a novel laccase gene mco was identified in a staphylococcal isolate S. haemolyticus NW19A. Mco was reconstructed and heterologously expressed in E. coli. The Mco enzymatic activity and tolerances to temperature, $\mathrm{pH}$, heavy metal ions, enzymatic inhibitors and organic solvents were investigated by using the 2,2'-azino-bis(3-ethylbenzthiazolinesulfonic acid) (ABTS) as a substrate. It has a high decolorization capability toward textile dyes. The three-dimensional (3D) structure of Mco was constructed to reveal a possible reason for its tolerances. The research presented herein 
provides a novel laccase Mco with a specific activity, thermal and $\mathrm{pH}$ stability, a wide substrate range and strong dye-decolorizing ability, which are of importance for industrial and agriculture processes such as biodegradation and bioremediation.

\section{Materials and Methods}

Microbial Strains, Media and Vectors

S. haemolyticus NW19A, an isolate from mastitis milk samples of Holstein cows was routinely maintained on Tryptic Soy Agar (TSA) at $37^{\circ} \mathrm{C}$. Escherichia coli DH5a were used for cloning procedures. Chaperone Competent Cell pG-KJE8/BL21 and plasmid pCold I were used for heterologous expression.

Cloning of $m c o$, Vector Construction and Bioinformatics Analysis

Genomic DNA of S. haemolyticus NW19A was purified by using an EasyPure Genomic DNA Kit (China). The laccase-like gene $m c o$ was amplified by PCR using the primers $m c o-\mathrm{F}$ (5'-TCCGAATTCGAAAGTAAGAATGAC ATGAT-3') and mco-R (5'-GACAAGCTTTTAGTTTGTTACTTTTATTT-3'). The underlined sequences represent the recognition sites of restriction enzymes EcoRI and HindIII, respectively. The amplified DNA fragment was purified using a Gel Extraction Kit (Transgen, China). The plasmid pCold I and purified PCR products were digested with EcoRI and HindIII. Then the mco gene was cloned into plasmid pCold I and expressed as a His-tagged form. For bioinformatics analyses, other laccase protein sequences from different microbial species were aligned with Mco using the ClustalX program. The conserved domains of Mco were predicted and analyzed using the conserved domain database [17]. The Homology Analysis was carried out with the neighbor-joining method (Mega software, Version 6.0).

\section{Expression and Purification of the Recombinant Laccase Mco}

The recombinant vector was transformed into the Chaperone Competent Cell E. coli pG-KJE8/BL21. Transformants were subsequently inoculated into $200 \mathrm{ml} \mathrm{LB}$ supplemented with $100 \mu \mathrm{g} / \mathrm{ml}$ ampicillin and incubated at $37^{\circ} \mathrm{C}$ and $220 \mathrm{rpm}$ until the turbidity reached 0.5 . Then, the culture was chilled to $15^{\circ} \mathrm{C}$ and added with $0.5 \mathrm{mg} / \mathrm{ml} \mathrm{L}$-arabinose, $5 \mathrm{ng} / \mathrm{mL}$ tetracycline and $0.1 \mathrm{mM} \mathrm{IPTG}$ in order to induce the expression of Mco. The culture was continuously incubated at $15^{\circ} \mathrm{C}$ for overnight. The cells were harvested by centrifugation at $12,000 \mathrm{~g}$ for $2 \mathrm{~min}$ and then resuspended in binding buffer $(20 \mathrm{mM}$ sodium phosphate, $15 \mathrm{mM}$ imidazole, $500 \mathrm{mM} \mathrm{NaCl}$, $\mathrm{pH}=7.4)$. The cells were lysed by sonication and the supernatant containing soluble recombinant protein Mco was gathered by centrifugation at $18,000 \mathrm{~g}$ for $30 \mathrm{~min}$ at $4^{\circ} \mathrm{C}$. Purification was performed on the HisTrap HP column system (GE Heathcare, USA). The crude fractions were dialyzed in TGE buffer at $4^{\circ} \mathrm{C}$ for $8 \mathrm{~h}$ to remove imidazole and were concentrated with Amicon ultrafiltration (membrane cutoff $10 \mathrm{kDa}, \mathrm{USA}$ ). Purification products were analyzed by SDS-PAGE to check the purity achieved in the purification procedure, using a $5 \%$ stacking gel and a $12 \%$ resolving gel. Protein bands were visualized by staining with Coomassie Brilliant Blue R-250. Protein concentration was determined using the Bradford Protein Assay Kit ( China) with bovine serum albumin as the standard. The purified laccase Mco was stored at $-80^{\circ} \mathrm{C}$ for further experiment.

\section{Enzyme Assay and Enzymatic Properties of Mco}

The ABTS (Sigma, USA) was used as a substrate to confirm the laccase activity, whose absorbance coefficient was: $\varepsilon_{420 \mathrm{~nm}}=36,000 \mathrm{M}^{-1} \mathrm{~cm}^{-1}$. One unit of enzyme activity (U) is defined as the amount of enzyme which oxidizes $1 \mu \mathrm{mol}$ of substrate per minute under the condition of $30^{\circ} \mathrm{C}$ and $\mathrm{pH} 4.5$. All of these laccase activity assays were determined in a reaction mixture at $150 \mu \mathrm{l}$ in a $100 \mathrm{mM}$ sodium acetate buffer $(\mathrm{pH} 4.5)$ at $30^{\circ} \mathrm{C}$ with ABTS at $1 \mathrm{mM}$ as the substrate [18]. For the Michaelis-Menten kinetics assay, gradient concentrations of ABTS ranging from $50 \mu \mathrm{M}$ to $1,000 \mu \mathrm{M}$ and Mco $(5.21 \mathrm{mg} / \mathrm{l})$ were employed and $K_{\mathrm{m}}$ and $k_{\text {cat }}$ values were analyzed by the GraphPad Prism (Version 5.0) based on Lineweaver-Burk plots. To investigate the optimal pH and temperature tolerance of $\mathrm{Mco}$, a gradient of temperature range $\left(30 \sim 70^{\circ} \mathrm{C}\right)$ and a broad range of $\mathrm{pH}(2.0 \sim 12.0)$ were applied. The optimal $\mathrm{pH}$ value was determined in $100 \mathrm{mM}$ sodium acetate buffers ( $\mathrm{pH}$ 2.0 6.0), $100 \mathrm{mM}$ sodium phosphate buffers ( $\mathrm{pH}$ 6.0 8.0) and a $100 \mathrm{mM}$ glycine- $\mathrm{NaOH}$ buffer ( $\mathrm{pH}$ 9.0 12.0). For $\mathrm{pH}$ and thermal tolerance assays, Mco was pretreated under certain conditions for $30 \mathrm{~min}$ and $1 \mathrm{~h}$ respectively, as described previously and the activity was routinely measured. The effects of metal ions, organic solvents and inhibitors on laccase activity were tested using $1 \mathrm{mM} \mathrm{ABTS}$ as the substrate and Mco $(5.21 \mathrm{mg} / \mathrm{l})$ at a temperature of $25^{\circ} \mathrm{C}$ and $\mathrm{pH} 4.5$ in sodium acetate buffer. These inhibitors included $\mathrm{Co}^{3+}\left(\mathrm{CoCl}_{3}\right), \mathrm{Cu}^{2+}\left(\mathrm{CuSO}_{4}\right), \mathrm{Fe}^{2+}\left(\mathrm{FeCl}_{2}\right), \mathrm{Mn}^{2+}\left(\mathrm{MnCl}_{2}\right), \mathrm{Ni}^{2+}\left(\mathrm{NiSO}_{4}\right), \mathrm{Zn}^{2+}\left(\mathrm{ZnSO}_{4}\right)$, and $\mathrm{Ba}^{2+}\left(\mathrm{BaCl}_{2}\right)$ at a final concentration of $20 \mathrm{mM}$, organic solvents (acetone, DMSO, methanol, ethanol at a final volume fraction of $10 \%$ or $30 \%$ ), sodium dodecyl sulfate including SDS (final concentrations: $5 \mathrm{mM}$ and $2 \mathrm{mM}$ ), EDTA (final concentrations: $5 \mathrm{mM}$ and $20 \mathrm{mM}$ ), and DTT $(2 \mathrm{mM})$ [18-20]. The purified enzyme was preincubated with the metal ion or inhibitor for $15 \mathrm{~min}$ and the remaining activity was measured. All experiments were carried out in triplicate.

\section{Decolorization Ability of Mco}

The dye-decolorizing ability of laccase was evaluated using four analytically pure dyes (Sigma), up to a $15 \mathrm{~h}$ period. The reaction mixture respectively contained $50 \mathrm{mg} / \mathrm{l}$ congo red, brilliant green, bromophenol blue or $20 \mathrm{mg} / \mathrm{l}$ crystal violet, acetate buffer $(25 \mathrm{mM}, \mathrm{pH} 4.5)$ and purified enzyme $(0.05 \mathrm{U})$ [6]. The decolorizing ability was measured at $30^{\circ} \mathrm{C}$ after every $3 \mathrm{~h}$ interval by measuring the absorbance at $625 \mathrm{~nm}$ for brilliant green, $490 \mathrm{~nm}$ for congo red, $592 \mathrm{~nm}$ for bromophenol blue, and $584 \mathrm{~nm}$ for crystal violet. The decolorization of dye, expressed as 


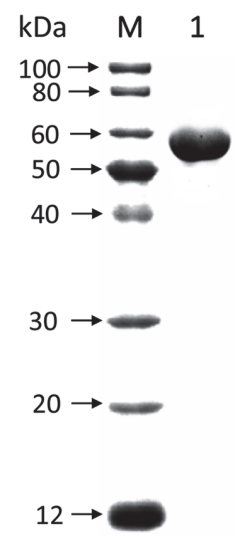

Fig. 1. SDS-PAGE analysis of the recombinant laccase Mco from S.haemolyticus NW19A. Lane M: protein marker; lane 1: purified laccase Mco.

dye decolorization (\%), was calculated by using the following formula: decolorization $(\%)=[(\mathrm{Ci}-\mathrm{Ct}) / \mathrm{Ci}] \times 100$, where, $\mathrm{Ci}$ : initial concentration of the dye, Ct: dye concentration along the time [21]. All assays were performed in triplicate.

\section{Modeling of Three-Dimensional Structure of Mco}

Swiss-Model (https://www.swissmodel.expasy.org/) was used to create the three-dimensional structure of Mco. The template structure is $3 \mathrm{nsf}$ ( $\mathrm{PDB}$ code), which shares the highest sequence identity (37.87\%) with Mco among the proteins in the Protein Data Bank (PDB) (http://www.rcsb.org/).

\section{Results and Discussion}

Heterologous Production and Activity of a Recombinant Laccase Mco

In order to identify the laccase activity of a multicopper oxidase from staphylococci, a 1,437bp ORF was amplified from the genome of $S$. haemolyticus NW19A and subsequently designated as mco (Fig. S1, GenBank Accession No. KM369884 (region: 61756-63192)) [22]. It encoded a protein with 478 amino acids and a molecular weight of $54.4 \mathrm{kDa}$ (Fig. 1). Mco was expressed in E. coli and purified using nickel affinity chromatography. The purified Mco exhibited a specific activity of $34.0 \mathrm{U} / \mathrm{mg}$ when using ABTS as a substrate. According to the Lineweaver-Burk plots, $K_{\mathrm{m}}$ and $k_{\text {cat }}$ values were $139.8 \mu \mathrm{M}$ and $6.87 \mathrm{~s}^{-1}$, respectively, falling within the range compared with other bacterial laccases.

The $K_{\mathrm{m}}$ for ABTS was $430 \mu \mathrm{M}$ and $290 \mu \mathrm{M}$ for two laccases from Trametes versicolor, with $V_{\max }$ values of $51.28 \mathrm{U} / \mathrm{mg}$ and $62.89 \mathrm{U} / \mathrm{mg}$, respectively [23]. The $K_{\mathrm{m}}$ value of the laccase from basidiomycete Fomitella fraxinea for ABTS was $270 \mu \mathrm{M}$ [24]. $K_{\mathrm{m}}$ value of an extracellular laccase from white-rot fungus Marasmius scorodonius was $27 \mu \mathrm{M}$ for ABTS [25]. A laccase Lac1326 from a marine metagenomic library showed a $K_{\mathrm{m}}$ value of $210 \mu \mathrm{M}$ for ABTS and a
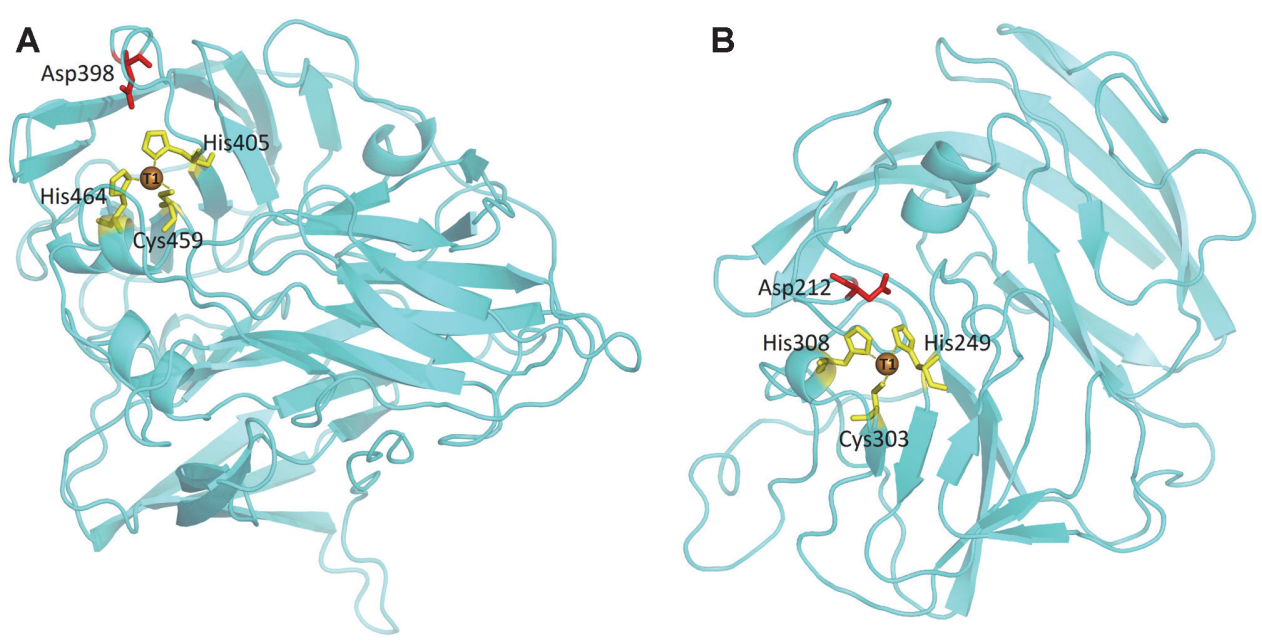

Fig. 2. The predicted 3D structure of Mco (A) and Atm (B). The conserved histidine and systeine residues of the copper-binding motifs, as well as the aspartic acid residue Asp located in the vicinity of the substrate binding site cavity of laccases are shown. 

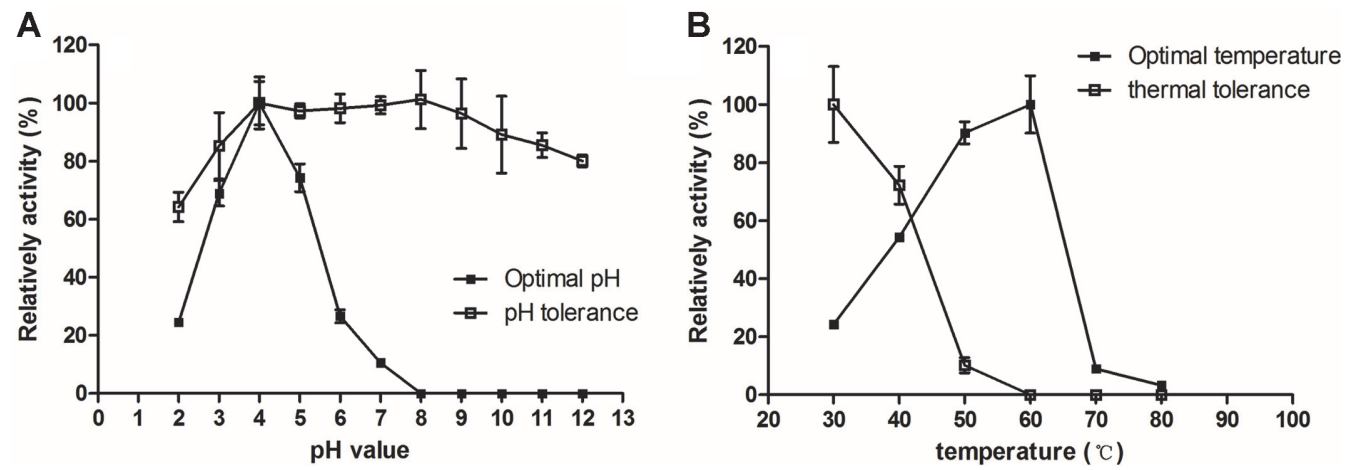

Fig. 3. (A) The optimal $\mathrm{pH}$ and $\mathrm{pH}$ tolerance was evaluated at $30^{\circ} \mathrm{C}$ over a $\mathrm{pH}$ range of $2.0 \sim 12.0$. (B) The optimal temperature and thermal tolerance of $\mathrm{Mco}$ were determined at various temperatures $\left(30^{\circ} \mathrm{C} \sim 80^{\circ} \mathrm{C}\right)$ and at $\mathrm{pH} 4.5$. The activity measured at $\mathrm{pH} 4.5$ and at $30^{\circ} \mathrm{C}$ was considered as $100 \%$. Error bars represent the standard errors of the means.

$V_{\max }$ value of $22.82 \mathrm{U} / \mathrm{mg}$ [26]. A Met-rich secondary structure was reported to occupy the T1 Cu site of many laccases and impair the ability to efficiently bind to the large substrate [10]. The Met-rich segment was absent in Mco, which may improve its substrate binding ability and catalytic activity (Fig. 2A).

\section{Thermal Stability and pH Stability of Mco}

The purified Mco exhibited its maximum activity at temperature $60^{\circ} \mathrm{C}$ and $\mathrm{pH} 4.0$. The identified Mco tolerated a wider range of $\mathrm{pH}$ with more than $80 \%$ of enzymatic activity remaining between the ranges from $\mathrm{pH} 3.0$ to $\mathrm{pH} 12.0$ after $1 \mathrm{~h}$ treatment (Fig. 3A). Furthermore, the Mco retained approximately $72.2 \%$ of activity after incubation at $40^{\circ} \mathrm{C}$ for $30 \mathrm{~min}$, but the activity was sharply reduced to $10.1 \%$ when the temperature was increased to $50^{\circ} \mathrm{C}$. Almost no activity was observed at $60^{\circ} \mathrm{C}$ after $30 \mathrm{~min}$ of incubation (Fig. 3B). Enzymes with a high level of intrinsic thermal stability, which were prevailingly cloned from extremophiles, are desirable and suitable for industrial applications [15]. Staphylococci usually colonize in animals and their enzymes always work at $37^{\circ} \mathrm{C}$, which might be a reason for their low thermal stability.

Generally, bacterial laccases show maximal catalytic rates in the neutral to alkaline $\mathrm{pH}$ range and fungal laccases show a preference for the acidic $\mathrm{pH}$ range [27]. Conserved acid amino acid residues Asp or Glu were located in the vicinity of the substrate binding site cavity of all known fungal laccases and were proposed to have a role in stabilizing the phenoxy radical formed during the catalytic reaction, but they were not present in any bacterial laccase identified so far [28]. In order to explore the possible reason why the optimal pH of Mco is acidic, the 3D structure of it was constructed, by utilizing a homology modeling approach via the Swiss-Model webserver. Not surprisingly, aspartic acid residue Asp398 was located in the vicinity of the substrate binding site cavity of Mco (Fig. 2A). Another bacterial originated laccase, Atm, identified by our lab, exhibited the maximal activity at pH 4.5 [29]. Amino acid residue Asp212 was also found in that site by modeling its 3D structure here (Fig. 2B). As far as we are concerned, it is the first time to reveal the possible reason for a bacterial laccase with acidic optimal $\mathrm{pH}$.

Tolerances of Mco to Heavy Metals, Enzyme Inhibitors and Organic Solvents

Heavy metal ions, enzyme inhibitors and organic solvents are commonly used in many industrial processes and can influence the activity and stability of laccases. Consequently, the tolerances of Mco to heavy metals were determined. In the present study, the tolerances of Mco to heavy metals were assessed with the results shown in

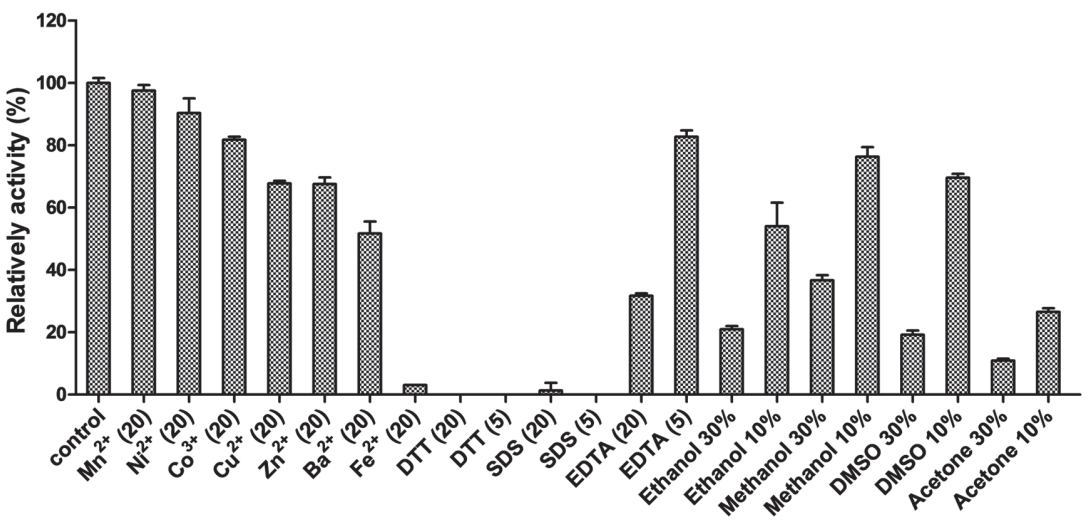

Fig. 4. Effect of heavy metals (mM), organic solvents (\%) and enzyme inhibitors ( $\mathrm{mM})$ on the enzymatic activity of Mco. Error bars represent the standard errors of the means. 


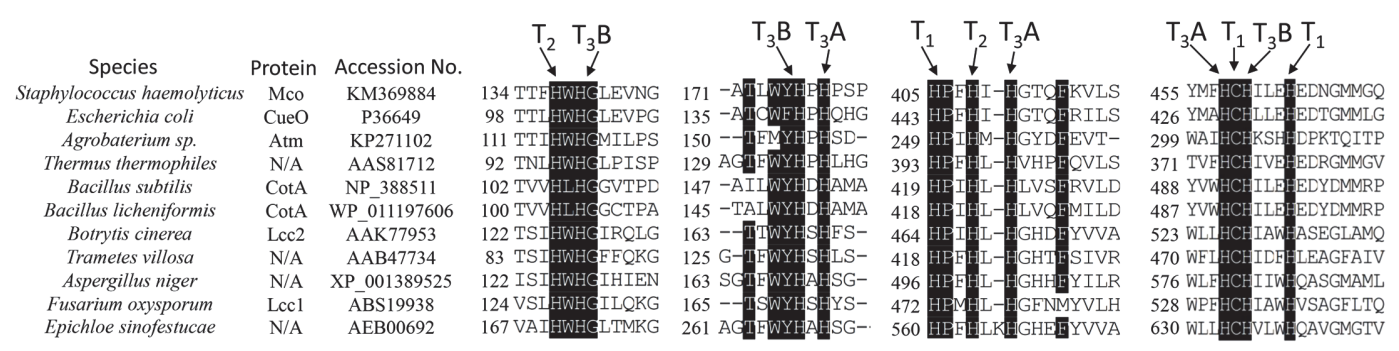

Fig. 5. Multiple sequence alignment of the four copper-binding domains of Mco, several bacterial laccases, and fungal laccases. The four conserved copper-binding domains are indicated (boxed).

Fig. 4. No significant inhibition was observed for Mco with $20 \mathrm{mM} \mathrm{Mn^{2+ }}$ used (97.5\% remaining). The Mco activity was partially inhibited by $\mathrm{Ni}^{2+}, \mathrm{Co}^{3+}, \mathrm{Cu}^{2+}, \mathrm{Zn}^{2+}$, and $\mathrm{Ba}^{2+}$ (ranging from $51.7 \%$ to $90.3 \%$ ) and completely inhibited by $\mathrm{Fe}^{2+}$ (3.1\% remaining) at $20 \mathrm{mM}$. Furthermore, Mco exhibited excellent tolerance to EDTA, with $82.7 \%$ and $31.7 \%$ of the activity remaining at $5 \mathrm{mM}$ and $20 \mathrm{mM}$ of EDTA, respectively. This laccase maintained $54.0 \%, 76.3 \%, 69.6 \%$, and $26.6 \%$ activities in the presence of $10 \%$ ethanol, methanol, DMSO and acetone, respectively. Moreover, the activities were not completely inhibited in all the tested solvents even at the concentrations of $30 \%$. DTT and SDS completely inactivated the enzyme under the current test concentrations. Mco showed similar heavy metal tolerances to laccases from fungus Fusarium solani MAS2 and bacterial Agrobacterium sp. S5-1 for many metal ions, in addition, showed higher tolerances to $\mathrm{Mn}^{2+}, \mathrm{Ni}^{2+}$, and $\mathrm{Co}^{3+}$ than the laccase from MAS2 and higher tolerances to $\mathrm{Ni}^{2+}$ and $\mathrm{Zn}^{2+}$ than the laccase from S5-1 $[18,36]$. The effect of metal ions on laccases depends on the binding site of metals and the size of the substrate binding cavity $[15,37,38]$.

\section{Sequence Characteristics and Distribution of mco}

Identifying the strictly conserved histidine residues of the copper-binding motifs is the main strategy to discover novel laccases. Four histidine-rich copper-binding domains were highly conserved in Mco in comparison with other bacterial and fungal laccases (Fig. 5) [30]. The phylogenetic relationship between Mco and other reported fungal as well as bacterial laccases was analyzed (Fig. 6). Mco shared the highest amino acid sequence identity of $35 \%$ with the characterized laccase $\mathrm{CueO}$ from E. coli. The overall similarity of the Mco to other bacterial laccases is low but higher than that to fungal laccases (Fig. 6).

Based on the BLASTN results from the NCBI nr/nt database, $m c o$ was found to be widely distributed (Table S1). Among the top 49 matched sequences with the highest similarities to $m c o, 22$ of them were located in bacterial genome ( 5 in S. haemolyticus, 7 in S. epidermidis and 10 in S. aureus) and 27 in bacterial plasmids (16 in S. aureus and 11 in Listeria monocytogenes). The presence of the mco gene in mobile genetic elements, such as staphylococcal cassette chromosome element and plasmids [22], is very important. It implies that the mco gene could be transferred horizontally among myriad kinds of staphylococcal isolates. The C-terminal segment of Mco in S. haemolyticus (amino acids 388 to 477) was absent in the Mco of Listeria monocytogenes. A C-terminus tail of 13-14 amino acids exhibits positive effects in the stability and laccase activity [10], and thus Mco in Listeria monocytogenes may perform low levels of stability and laccase activity. Low valence metal ions, such as $\mathrm{Cu}^{+}$and $\mathrm{Fe}^{2+}$, generate toxic hydroxyl radicals in bacteria via the Fenton reaction [39]. The oxidation of them to high valence ions by laccase would protect bacteria against metal ion-promoted oxidative stress $[39,40]$. The ability to mitigate endogenous and exogenous oxidative stress by obtaining a multitude of oxidative defense strategies

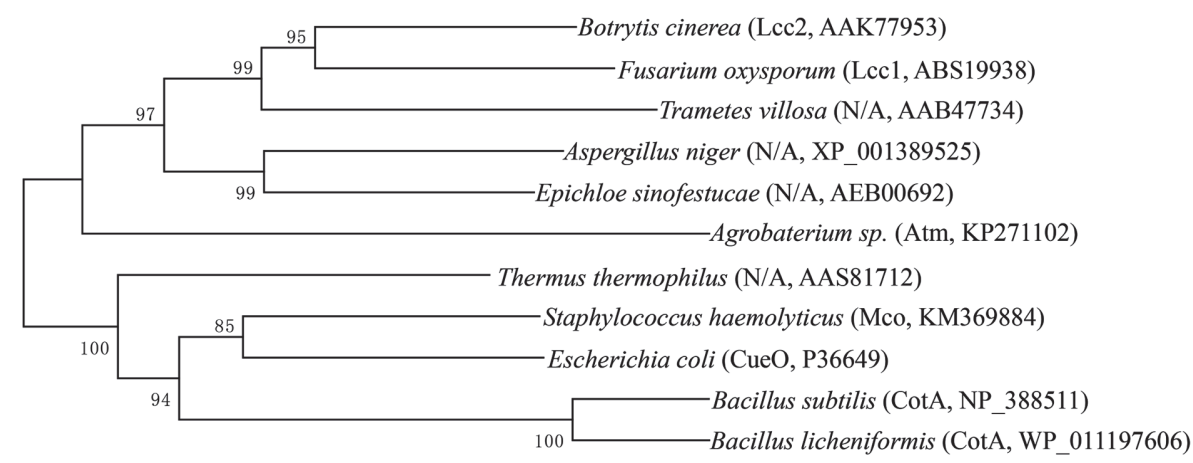

Fig. 6. The phylogenetic analysis by a neighbor-joining method (Mega software, Version 6.0) utilizing the deduced amino acid sequences of Mco and other fungal and bacterial laccase protein sequences. Bootstrap values were obtained from 1000 repetitions and illustrated as percentages at the nodes. The evolutionary distance of 0.2 amino acid substitutions per position was represented at the scale bars. I and II represented laccases from fungi and bacteria, respectively. 


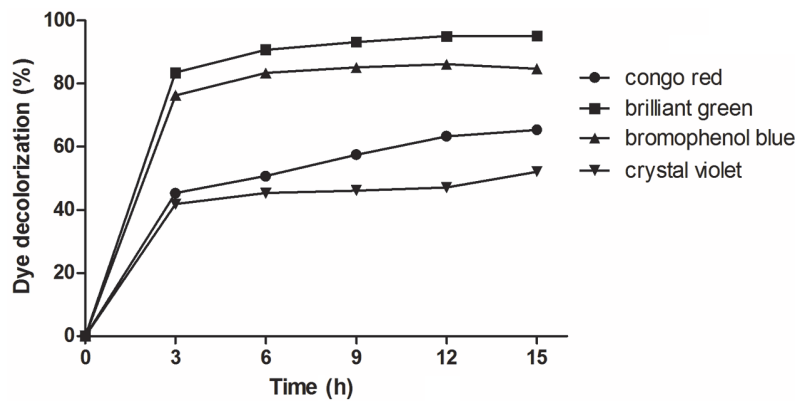

Fig. 7. Decolorization of dyes by the purified Mco.

accounts for staphylococci becoming a successful pathogen [41]. We propose that the laccase activity of Mco in staphylococci and its wide distribution in different staphylococcal species add a new oxidative defense strategy for staphylococci which should be paid attention to in future study.

\begin{abstract}
Ability of Mco on Decolorization
Decolorization of textile dyes is one of the most desirable applications for bacterial laccases [31]. Dyeing and textile industries account for a huge volume of highly colored dye effluents released into the environment. Triarylmethane and azo serve as the most commonly used dyes in the textile industry. Laccases can demethylate the triarylmethane or disassemble the azo bond of azo dye [1]. Therefore, the four representative dyes (three triarylmethane dyes as brilliant green, bromophenol blue and crystal violet and one azo dye congo red) were used to evaluate the decolorization ability of Mco (Fig. 7). Under the treatment of Mco at $3 \mathrm{~h}$, more than $40 \%$ was decolorized for each dye. The decolorization efficiency of Mco to congo red, brilliant green, bromophenol blue and crystal violet after $15 \mathrm{~h}$ were $65.3 \%, 95.1 \%, 84.61 \%$, and $52.1 \%$ in the absence of mediators, respectively.

In conclusion, the laccase has been isolated from a number of bacterial species including Azospirillum lipoferum, Bacillus subtilis, Bordetella campestris, Caulobacter crescentus, Escherichia coli, Marinomonas mediterranea, Mycobacterium tuberculosum, Pseudomonas aeruginosa, Pseudomonas syringae, Stenotrophomonas maltophilia, Streptomyces griseus and Yersinia pestis, but never from any staphylococci [2]. Hence, to the best of our knowledge, this Mco is the first identified laccase in staphylococci. The findings of our study showed that Mco exhibited high tolerances towards a wide range of $\mathrm{pH}$, majorities of heavy metal ions and organic solvents. The high efficiency of dye decolorization by Mco was observed in the absence of mediators. Most mediators generate highly unstable radical intermediates toxic to the environment, and thus the addition of mediators in dye decolorization systems has no advantage in practical applications $[32,33]$. The difference in the molecular structure of the dyes was proposed to be the reason for the variation in the decolorization efficiency [34]. These properties make this laccase Mco a suitable candidate for industrial applications such as textile finishing or wastewater treatment for energy-saving and low-cost purposes $[32,35]$. Possible industrial applications of this novel enzyme should be explored in detail in a future study, including its ability to degrade a wider range of industrial dyes as well as substrate specificity. Its wide distribution and potential role in oxidative defense ability may contribute to staphylococci colonization and survival.
\end{abstract}

\title{
Acknowledgments
}

This work was supported by two grants from the National Natural Science Foundation of China (grant no. 31972652 and 31602023).

\section{Conflict of Interest}

The authors have no financial conflicts of interest to declare.

\section{References}

1. Martins LO, Durao P, Brissos V, Lindley PF. 2015. Laccases of prokaryotic origin: enzymes at the interface of protein science and protein technology. Cell Mol. Life Sci. 72: 911-922.

2. Senthivelan T, Kanagaraj J, Panda RC. 2016. Recent trends in fungal laccase for various industrial applications: an eco-friendly approach - a review. Biotechnol. Bioprocess Eng. 21: 19-38.

3. Morozova V, Shumakovich GP, Gorbacheva MA, Shleev SV, Yaropolov AI. 2007. "Blue" laccases. Biochemistry 72: 1136-1150.

4. Rivera-Hoyos CM, Morales-Alvarez ED, Poutou-Pinales RA, Pedroza-Rodriguez AM, Rodriguez-Vazquez R, Delgado-Boada JM. 2013. Fungal Biol. Rev. 27: 67-82.

5. Dwivedi UN, Singh P, Pandey VP, Kumar A. 2011. Structure-function relationship among bacterial, fungal and plant laccases. J. Mol. Catal. B-Enzym 68: 117-128.

6. Fan FF, Zhuo R, Sun S, Wan X, Jiang ML, Zhang XY, Yang Y. 2011. Cloning and functional analysis of a new laccase gene from Trametes sp 48424 which had the high yield of laccase and strong ability for decolorizing different dyes. Bioresour. Technol. 102: 3126-3137.

7. Fang Z, Li TL, Wang QA, Zhang XC, Peng H, Fang W, et al. 2011. A bacterial laccase from marine microbial metagenome exhibiting chloride tolerance and dye decolorization ability. Appl. Microbiol. Biotechnol. 89: 1103-1110. 
8. Santhanam N, Vivanco JM, Decker SR, Reardon KF. 2011. Expression of industrially relevant laccases: prokaryotic style. Trends Biotechnol. 29: 480-489.

9. Reiss R, Ihssen J, Thony-Meyer L. 2011. Bacillus pumilus laccase: a heat stable enzyme with a wide substrate spectrum. BMC Biotechnol. 11: 9. doi: 10.1186/1472-6750-11-9.

10. Sitarz AK, Mikkelsen JD, Meyer AS. 2016. Structure, functionality and tuning up of laccases for lignocellulose and other industrial applications. Crit. Rev. Biotechnol. 36: 70-86.

11. Gupta N, Lee FS, Farinas ET. 2010. Laboratory evolution of laccase for substrate specificity. J. Mol. Catal. B-Enzym. 62: 230-234.

12. Xue HP, Zhou JG, You C, Huang Q, Lu H. 2012. Amino acid substitutions in the N-terminus, cord and alpha-helix domains improved the thermostability of a family 11 xylanase XynR8. J. Ind. Microbiol. Biotechnol. 39: 1279-1288.

13. Sharma P, Goel R, Capalash N. 2007. Bacterial laccases. World J. Microbiol. Biotechnol. 23: 823-832.

14. Ruijssenaars HJ, Hartmans S. 2004. A cloned Bacillus halodurans multicopper oxidase exhibiting alkaline laccase activity. Appl. Microbiol. Biotechnol. 65: 177-182.

15. Miyazaki K. 2005. A hyperthermophilic laccase from Thermus thermophilus HB27. Extremophiles 9: 415-425.

16. Ayed L, Bakir K, Ben Mansour H, Hammami S, Cheref A, Bakhrouf A. 2017. In vitro mutagenicity, NMR metabolite characterization of azo and triphenylmethanes dyes by adherents bacteria and the role of the "cna" adhesion gene in activated sludge. Microb. Pathog. 103: $29-39$.

17. Marchler-Bauer A, Zheng CJ, Chitsaz F, Derbyshire MK, Geer LY, Geer RC, et al. 2013. CDD: conserved domains and protein threedimensional structure. Nucleic Acids Res. 41: D348-D352.

18. Si W, Wu ZW, Wang LL, Yang MM, Zhao X. 2015. Enzymological characterization of Atm, the first laccase from Agrobacterium sp. S5-1, with the ability to enhance In Vitro digestibility of Maize Straw. PLoS One 10(5): e0128204.

19. Wu J, Kim KS, Lee JH, Lee YC. 2010. Cloning, expression in Escherichia coli, and enzymatic properties of laccase from Aeromonas hydrophila WL-11. J. Environ. Sci.-China 22: 635-640.

20. Ai MQ, Wang FF, Huang F. 2015. Purification and characterization of a thermostable laccase from Trametes trogii and its ability in modification of kraft lignin. J. Microbiol. Biotechnol. 25: 1361-1370.

21. Lorenzo M, Moldes D, Sanroman MA. 2006. Effect of heavy metals on the production of several laccase isoenzymes by Trametes versicolor and on their ability to decolourise dyes. Chemosphere 63: 912-917.

22. Xue HP, Wu ZW, Li LP, Li F, Wang YQ, Zhao X. 2015. Coexistence of heavy metal and antibiotic resistance within a novel composite Staphylococcal cassette chromosome in a Staphylococcus haemolyticus isolate from bovine mastitis milk. Antimicrob. Agents Chemother. 59: 5788-5792.

23. Qi Li, Lin Ge, Junli Cai, Jianjun Pei, Jingcong Xie, Linguo Zhao. 2014. Comparison of two laccases from Trametes versicolor for application in the decolorization of dyes. J. Microbiol. Biotechnol. 24: 545-555.

24. Park K M, Park S S. 2008. Purification and characterization of laccase from basidiomycete Fomitella fraxinea. J. Microbiol. Biotechnol. 18: $670-675$.

25. Jeon S J, Lim S J. 2017. Purification and characterization of the laccase involved in dye decolorization by the white-rot fungus Marasmius scorodonius. J. Microbiol. Biotechnol. 27: 1120-1127.

26. Qihao Yang, Mengle Zhang, Manman Zhang, Chunqing Wang, Yanyan Liu, Xinjiong Fan et al. 2018. Characterization of a novel, cold-adapted, and thermostable laccase-like enzyme with high tolerance for organic solvents and salt and potent dye decolorization ability, derived from a marine metagenomic library. Front. Microbiol. 9: 2998.

27. Lígia O Martins, Paulo Durão, Vânia Brissos, Peter F Lindley. 2015. Laccases of prokaryotic origin: enzymes at the interface of protein science and protein technology. Cell. Mol. Life Sci. 72: 911-922.

28. CMadzak, M C Mimmi, E Caminade, A Brault, S Baumberger, P Briozzo, et al. 2006. Shifting the optimal pH of activity for a laccase from the fungus Trametes versicolor by structure-based mutagenesis. Protein Eng. Des. Sel. 19: 77-84.

29. Wei Si, ZhaoWei Wu, LiangLiang Wang, MingMing Yang, Xin Zhao. 2015. Enzymological characterization of Atm, the first laccase from Agrobacterium sp. S5-1, with the ability to enhance in vitro digestibility of maize straw. PLoS One 10: 0128204.

30. Ye M, Li G, Liang WQ, Liu YH. 2010. Molecular cloning and characterization of a novel metagenome-derived multicopper oxidase with alkaline laccase activity and highly soluble expression. Appl. Microbiol. Biotechol. 87:1023-1031.

31. Arora DS, Sharma RK. 2010. Ligninolytic fungal laccases and their biotechnological applications. Appl. Biochem. Biotechnol. 160: 1760-1788.

32. Fang ZM, Li TL, Chang F, Zhou P, Fang W, Hong YZ, et al. 2012. A new marine bacterial laccase with chloride-enhancing, alkalinedependent activity and dye decolorization ability. Bioresour. Technol. 111:36-41.

33. Moldes D, Sanroman MA. 2006. Amelioration of the ability to decolorize dyes by laccase: relationship between redox mediators and laccase isoenzymes in Trametes versicolor. World J. Microbiol. Biotechol. 22: 1197-1204.

34. Claus H, Faber G, Konig H. 2002. Redox-mediated decolorization of synthetic dyes by fungal laccases. Appl. Microbiol. Biotechnol. 59: $672-678$.

35. Morita Y, Nakamura T, Hasan Q, Murakami Y, Yokoyama K, Tamiya E. 1997. Cold-active enzymes from cold-adapted bacteria. J. Am. Oil. Chem. Soc. 74: 441-444.

36. Wu YR, Luo ZH, Chow RKK, Vrijmoed LLP. 2010. Purification and characterization of an extracellular laccase from the anthracenedegrading fungus Fusarium solani MAS2. Bioresour. Technol. 101: 9772-9777.

37. Si J, Peng F, Cui BK. 2013. Purification, biochemical characterization and dye decolorization capacity of an alkali-resistant and metal-tolerant laccase from Trametes pubescens. Bioresour. Technol 128: 49-57.

38. Ma J, Xu ZS, Wang F, Xiong AS. 2015. Isolation, purification and characterization of two laccases from carrot (Daucus carota L.) and their response to abiotic and metal ions stresses. Protein J. 34: 444-452.

39. Baker J, Sitthisak S, Sengupta M, Johnson M, Jayaswal RK, Morrissey JA. 2010. Copper stress induces a global stress response in Staphylococcus aureus and represses sae and agr expression and biofilm formation. Appl. Environ. Microb. 76: 150-160.

40. Tree JJ, Ulett GC, Ong CLY, Trott DJ, McEwan AG, Schembri MA. 2008. Trade-off between iron uptake and protection against oxidative stress: Deletion of $\mathrm{cueO}$ promotes uropathogenic Escherichia coli virulence in a mouse model of urinary tract infection. J. Bacteriol. 190: 6909-6912.

41. Gaupp R, Ledala N, Somerville GA. 2012. Staphylococcal response to oxidative stress. Front. Cell Infect. Microbiol. 2: 33. 